\title{
The Chiasmus of Design: Paradoxical Outcomes in the e-Government Reform of UK Children's Services
}

\author{
David Wastell ${ }^{1}$, Sue White ${ }^{2}$, and Karen Broadhurst ${ }^{2}$ \\ ${ }^{1}$ Nottingham University Business School, UK \\ ${ }^{2}$ Department of Applied Social Science, \\ University of Lancaster, UK
}

\begin{abstract}
This paper describes a detailed ethnographic study of the design problems of a major national IT system in the UK- The Integrated Children's System (ICS). The implementation of the ICS has disrupted social work practice and engendered growing professional resistance, prompting a fundamental review of its design. Marshall McLuhan's concept of chiasmus is a central feature of our analysis of the vicissitudes of ICS. Chiasmus refers to the tendency of any system, when pushed too far, to produce unintended contradictory effects, and is an intrinsic feature of the behaviour of complex, socio-technical systems. The dysfunctions of the ICS provide a pertinent, large-scale example. The ICS constitutes an attempt, via technological means, to re-organize child welfare services in the UK. Whilst aimed at improving child safety, the ICS has had the opposite effect of increasing the potential for error. This chiasmus has been exposed through the multi-site ethnography reported here, which shows how rigidly designed processes, enforced by IT systems, force social work professionals into unsafe investigative and recording practices which increase the risk of errors. The paper ends by proposing an alternative approach to design, based on socio-technical precepts, emphasizing the principles of minimum critical specification, user-centeredness and local autonomy.
\end{abstract}

\section{Introduction}

UNISON wishes to draw attention to the seriousness of the problems being experienced by social work staff with the Integrated Children's System. The problems appear to be fundamental, widespread and consistent enough to call into question whether the ICS is fit for purpose.... we have reports of a number of industrial disputes or collective grievances brewing or underway and in many more cases staff are voting with their feet and not using the system when they can get away with it (Unison, 2008).

The above quotation is taken from the submission of the UNISON trade union (to which many UK social workers belong) to the independent enquiry recently set in train by the Secretary of State for Children, Schools and Families, Ed Balls, in response to the tragic and brutal death of a 17 month old child ("Baby P") in the London Borough of Haringey in August 2007. The trial of the child's mother, 
boyfriend and another man, which concluded in November 2008, was widely reported in the British press and caused considerable moral outrage. Significant short-comings in the child protection services in the Borough were brought to light. As well as the enquiry, a national "Social Work Task Force" was also set up, charged with a fundamental review of all aspects of front-line social work practice. Press reports of the case drew attention to the deficiencies of a national IT system designed for children's services, and the role that this was playing in undermining safe professional practice. This is the Integrated Children's System (ICS) referred to in our epigraph. An article in the Guardian newspaper of $19^{\text {th }}$ November (p. 7) is typical of the coverage: entitled "Child protection stifled by $£ 30 \mathrm{~m}$ computer system", the article highlighted the vast amount of time taken "filling out forms" on ICS and the pressures created by the system's deadlines, together acting to "restrict the time available for family visits". The urgent need to review the design of ICS is one of the priority areas for the above-mentioned Task Force ${ }^{1}$.

The failure of IT projects is by no means a new phenomenon (Beynon-Davies, 2009), with a research literature reaching back to the classic papers of the discipline (e.g. Markus, 1983) over twenty five years ago. In this article, we shall focus our analysis on the failings of the ICS, attempting to tease out the fatal flaws responsible for the paradox of a system designed to enhance child safety seemingly having the contrary effect. As a major national initiative directly aimed at transforming social work practice, ICS is worthy of investigation in its own right. With a total professional workforce of around 20,000 social workers and care managers, and an annual budget for children's social services of over $£ 5$ billion per annum, it is vital to understand its defects in order to devise appropriate and efficacious remedies. We also believe that the problems inherent in ICS are by no means unique, and that there are lessons to be learned for the design of IT systems in general. These lessons are especially relevant in the context of public sector reform where technology features so centrally as the instrument of "modernization", with e-Government now embedded as a global phenomenon (Wastell, 2006).

Marshall McLuhan's concept of chiasmus plays a central role in our analysis. In typically gnomic style, McLuhan defines chiasmus as "the reversal of process caused by increasing its speed, scope or size - every process pushed far enough tends to reverse or flip suddenly" (McLuhan and Carson, 2003, p. 222). Chiasmus emphasizes the indeterminacy of design, especially in the context of complex systems (where the presence of multiple, interacting variables means that outcomes are inherently unpredictable) and is a much-needed antidote to simplistic cause-effect thinking. In the case of ICS, the "process pushed too far" is regulation; through an excess of formalisation and control, aimed an enhancing professional performance. ICS instead disrupts that practice and engenders widespread resistance from its users, as exemplified in the opening quotation. The dangers of over-specification and the need to find the golden mean, the right balance of structure and discretion, are central in designing any system and are well-known in organisational theory. As Argyris (1999) put it "All organisations are designs... managers specify ahead of time the jobs and roles of the players as completely as possible without the specifications being so complex that they immobilise performance". The socio-technical theorists propound

\footnotetext{
${ }^{1}$ As a result of the research reported here, one of the authors (SW) is a member the Task Force.
} 
the same wisdom: "details of a work system should not be overspecified in advance. Sociotechnical analysis proceeds by specifying ... only those things that must be defined: the minimum critical specification" (Pava, 1983). Sadly, this core precept of design seems not to have been known to the architects of the ICS.

In the next section, we will briefly set out the main theoretical ideas which our analysis will draw on, namely the systems approach to error management, and the work of James Reason in particular (Reason, 1997; 2000). We then introduce the organisational context for our research, the referral and assessment process for children's services. We will contend that the analysis of errors in organizational settings should focus on systemic weaknesses, in particular the "latent conditions" for error (Reason, 1997; 2000) which generally increase the risk of failure. We then present our empirical findings in detail, describing the results of our multi-site ethnographic investigation of the impact of ICS on child welfare practices, presenting evidence that policy initiatives to enhance child safety have had the contrary effect. These paradoxical outcomes are subtle though, only to be teased out by careful, ethnographic analysis of the local adaptations of practice arising from the user/technology interaction ${ }^{2}$. Our conclusions will, inter alia, reiterate the imperative for a thorough understanding of the needs of users and their working practices in system design.

\section{The Systems Approach to Error Management in the Context of "Modernised" Children's Services}

There is a substantive body of work that argues for such a systems approach to error management (Reason, 1997; Munro, 2005a; Bostock et al., 2005). Reason (1997; 2000), perhaps the most well known exponent of this standpoint, argues that errors in human systems have their origins "not so much in the perversity of human nature as in upstream, systemic factors" (p768, 2000). Coining the notion of "latent conditions for error", he argues that the analysis of errors in organizational settings should focus on general systemic weaknesses, rather than mistakes made by particular individuals on particular occassions. Such latent conditions refer to generalised, immanent characteristics of a designed system (typically non-obvious and unintended) that increase the risk of errors occurring in the operational situation. In aviation, for instance, efforts to automate pilot functions were based on the premise that this would improve safety (Norman, 1990). However, by displacing the pilot from the "control loop", his/her grasp of what was currently going on in relation to the the status of aeroplane, was necessarily eroded. Such reduction of "situational awareness" provides an example of a latent condition of error, a direct paradoxical consequence of infelicitous design. When the pilot was obliged to take over control in exceptional conditions, the likelihood of mistakes was increased and indeed several serious accidents were attributed to such a causal pattern (Norman, 1990).

${ }^{2}$ We use "technology" in its widest sense to encompass formally-defined procedures and methods (administrative technology) as well as physical machinery, such as the ubiquitous personal computer. 
An extensive quotation from Reason (2000, p.769) provides a useful summary of the main features of the concept. Designating latent conditions as the inevitable "resident pathogens" within the system, he goes on:

They arise from decisions made by designers, builders, procedure writers, and top level management.... All such strategic decisions have the potential for introducing pathogens into the system. Latent conditions have two kinds of adverse effect: they can translate into error provoking conditions within the local workplace (for example, time pressure, understaffing, inadequate equipment, fatigue, and inexperience) and they can create long-lasting holes or weaknesses in the defences (untrustworthy alarms and indicators, unworkable procedures, design and construction deficiencies, etc). Latent conditions-as the term suggestsmay lie dormant within the system for many years before they combine with active failures and local triggers to create an accident opportunity.

From a systems perspective, approaches to error management that focus on individual breaches of procedure or unwanted aberrations of human conduct will inevitably be limited to delivering safer worker practices. Individuals are fallible and will always err, the trick is to design safe systems that minimise the likelihood and the consequentiality of such inevitable failures. A systems perspective requires that more attention be focused on minimizing "the number of latent conditions in the system that can contribute to user error" (Lowe, p.2, 2006).

The main interest of our ethnographic field work has centred on the interface (the "front door") between social services departments and other agencies (e.g. police, health services) and with the general public. Whilst the ICS covers all aspects of social work with children, from referral and assessment through to the provision of family support, the enactment of child protection procedures (including the potential removal of children into local authority care), it is the early assessment stages that have been particularly subject to "re-engineering", aimed at improving their safety and efficiency. In 2000, The Framework for the Assessment of Children in Need and their Families was introduced (Cleaver and Walker, 2004) which clearly defined the initial statutory response as a distinct stage in the assessment process (Horwath, 2002). Since its advent, the importance of initial assessment practices has been further reinforced by the public inquiry into the death of Victoria Climbie (Laming, 2003) which heavily criticised the social services department involved (Haringey was again involved) for failings in their referral and assessment processes.

Initial assessment (IA) emphasizes the importance of the initial professional response, especially the need to see the child at the earliest point. The Integrated Children's System (ICS) has accordingly been designed to ensure that workers follow the various steps specified in a formally defined "model" of the assessment process, creating a indelible, auditable trace of day-to-day practices. A standardised IA form prompts workers to collect information in a systematic way, with the expectation that the data so-garnered will contribute usefully to further assessment. Consistent with the universal application of Performance Management throughout the UK public sector (Bevan and Hood, 2006), a burgeoning range of targets and timescales have 
been stipulated. Within 1 day of a referral being received, social service departments are mandated to make and $\log$ a decision about the requisite response. When an initial assessment is deemed necessary, this must be completed within 7 days, including the requirement to see the child.

In this heavily regulated regime, latent conditions for error are all too readily found. Work volumes create severe pressures in most settings. It is estimated that, on average, some 300 referrals must be processed every month by the typical social services department ${ }^{3}$, although precise measures are difficult, given definitional issues and local practice adaptations. Teams are legally bound to respond to referrals; they receive no extra compensation or flexibility regarding staff sickness levels, rather targets must be met whatever the particulars of local context or case. Pressures are further compounded by the widespread problem of recruiting and retaining experienced staff (Audit Commission, 2002). Where referral rates are high and resources are constrained, trade offs are inevitable between urgent child-protection work and assessments leading to more generalised forms of family support. Our work draws attention to the short-cuts that the IA process necessitates, given the immutable timescales and excessive audit requirements it imposes. Imperatives to safeguard children and support families appeared at odds with, rather than enhanced by, new modes of e-governance and associated performance targets. In particular the procrustean timescales set for the completion of the initial assessment inevitably pushed workers to make precipitous categorisations based on, at best, one home visit. Equally, the standardised but tortuous assessment forms appeared to invite a range of problematic recording practices. The general aim of this paper is to draw attention to the unsafe practices that the ICS appeared to necessitate in its demand for rapid case disposals, and the latent error conditions that this ineluctably creates.

\section{The Field-Work and Findings}

The project comprised a multi-site ethnographic study, based in five local authorities in England and Wales and drawing data from 15 social work "initial assessment" teams. The five local authority areas comprise: a London borough (Metroville); a county council (Shire); a metropolitan borough in the North of England (Westford); a unitary authority (Seaton); a Welsh rural authority (Valleytown). The field-work began in 2007 and is still underway. Informed by appropriate standards for ethical research, the ethnographies have involved various levels of engagement across the sites. Everyday interactions between team leaders and social workers, middle and senior managers have been observed as well as more formal meetings. In total, we estimate that this has amounted to around 240 days of observation and analysis of everyday practice, including worker interactions and meetings, supplemented by the inspection of key documents and case files. In addition, a total of 10 focus groups and 60 formal interviews have also been conducted. Transcripts and fieldnotes were uploaded to a dedicated project web-site to allow the research team to share and discuss the data. Regular meetings were held to examine and validate emergent themes, supported by group email exchange and discussion. Through these means, we

\footnotetext{
${ }^{3}$ National performance statistics for England show an average monthly referral rate of 306 for 2006/07.
} 
have ensured that the pattern of findings reported below provides an accurate representation of the situation across the five sites.

Each of the five initial assessment teams is tasked to respond to initial contacts and referrals that come by way of telephone calls, faxes, emails, multi-agency assessment forms etc. These various external contacts cover the range from reports of serious injuries to children, more uncertain concerns about children's welfare, right through to simple requests for information and advice. In all sites, there is increasingly little opportunity for a "customer" to walk in and directly request help, rather all approaches are mediated through some form of "front of house" customer service interface, either centralised or within the team. Whilst practices varied across our sites, we found a number of distinct commonalities reflecting the influence of the performance management elements of ICS and the concomitant preoccupation of staff with maintaining "workflow". Workers consistently claimed that it was easy to lose sight of the primary activities of supporting families and safeguarding children, to the second order activities of performance and audit. In the rest of this Section, we will focus on the latent conditions for error created by this administrative regime embodied within the ICS. We illustrate these risky adaptations in the sub-sections that follow, limiting our report to three discrete aspects of the initial assessment process, (i) accepting a contact/referral (ii) making further enquiries and seeing the child and (iii) the completion of the IA record.

\subsection{Accepting a Contact/Referral}

Our assessment teams reported variable referral rates, ranging from 80 to figures significantly higher than 300 per month. In all but one site, far more contacts/referrals were received than could be managed. The requirment for an initial decision within 24 hours necessitates a rapid but not necessarily reliable response, and where workloads are high, the potential for error is clear:

Admin worker: The phone will be ringing continuously, you put the phone down and it rings straight away...one comes and another one comes... and your mind just gets frazzled, I might have written 5 or 6 pages of A4 paper ... and when I come back to reading them, it's all looking a bit messy...I can't quite make out what I've got down...

Such pressures created significant anxieties for experienced staff workers, who understood that the pace of work created less than ideal conditions for practice, but there was also evidence of 'speed-practices' becoming habituated and normalised, especially in newer staff. For staff higher up the hierarchy, it was critical that only a manageable number of referrals were actually allocated for initial assessment. In the extract below, taken from one of our busiest teams, the team leader makes clear her reasons for clearing contacts by the end of the day, in anticipation of tomorrow's influx. The practical mandate for her actions is directly related to the exigencies of managing work-flow dictated by performance timescales.

Team leader: 'There are 50 contacts in your inbox... you are under pressure because you have to clear them by the end of the day ... and the question of whether you are more likely to close them in these 
circumstances? Well yeah.. so, really we are looking to close cases not open them... that's why we work to the highest thresholds'

The IT systems maintained the pace of work, typically by providing digital reminders of deadlines and timescales. In one site, we found an 'e-tracking device' in the form of traffic lights, which informed workers about how much time was left before the specific episode was deemed out of timescale. In another site, 'higher management' were planning to print out weekly graphs of levels of attainment in meeting targets, alongside tables exposing individual failures.

In order to manage the volume of referrals, we consistently observed that the teams had well established 'general deflection strategies' that included: strategic deferment, i.e. sending the referral back to the referrer to ask for more information; and signposting, deflecting the case to a more 'appropriate' agency. Whilst such adaptations are sensible if proportionate, the inherent risks are also clear. Where insufficient time precluded the pursuit of more detailed information from a referrer, other decision-making heuristics came into play. These included the routine categorisation of anonymous referrals as malicious (indeed referrrals from neighbours and family members were also often treated as suspect). We were told that children aged over 13 were routinely 'NFA-ed' (an outcome of no further action was recorded) on the basis that these children and young people 'must have lived with these concerns for a long time and be quite resilient'. Similarly we found questionable methods for dealing with domestic violence notifications often on the basis of scant information. For example, in one site, first and second notifications were responded to automatically by a letter to parents; upon receipt of a third notification a visit would be made. We found that well-intentioned, but very busy workers, became habituated to these methods of rationing, with little time to reflect on, or question, such rationales and the risks they entailed.

In the following extract, the worker indicates how the imperative to prioritise a case already categorised as child protection (S47, i.e. section 47, Children Act 1989) required that she give less priority to an incoming referral, which also sounded malicious. Although she acknowledges her lack of knowledge, she justified her decision as follows:

Social worker: 'I've got this S47 and actually this family are in crisis and I want to put support in for them, before I worry about this other family that don't even know I'm coming, because it's an anonymous referral from a neighbour ... and you think, well OK, I don't know if there's a real risk or not, but from reading it it sounds a bit malicious, well this family, actually are about to fall apart if you don't put something in'

In order to manage workflow, we also observed some 'safer' locally-improvised methods for meeting timescales, that generally amounted to holding a case open for 'review', but logging the IA as complete on the system so as to meet the target. In cases where the seven days has not provided sufficient time to establish confidence about the child's welfare, this 'review space' could enable further information to be gathered. However, such workarounds, even when they are constructive, by their very nature can only survive while they remain undetected by inspecting agencies and their technological proxies. 


\subsection{Making Further Enquiries and Seeing the Child}

A number of cases will get through the first layer of filtering and be allocated to a social worker for initial assessment, which will include making further enquiries and seeing the child. At this second stage, we also found short-cuts in operation. There was a tendency to abort an assessment whenever the 'opportunity' arose. In the case of the referral from a grandmother below, the routine treatment of referrals from family members as potentially suspicious, and that the health visitor had seen the child, together enabled swift disposal of the case.

Team leader: Being a bit cheeky...we contacted the health visitor and said when did you last see the visitor and lucky enough the health visitor had seen the baby recently and it wasn't as bad as the grandmother had alleged..so we didn't take it any further, no further action

Workers widely reported that the timescales created undue pressure. One senior practitioner observed: "I personally worry about sometimes the time scales that you've, you've got to do it in ...I've been sort of worrying about work for, for a while really". The tempo and volume of work, together with the 7-day target for IA completion, were widely reported as making cases at this second stage equally susceptible to partial analysis and rapid disposal.

Social worker: If it's not looking that serious... sometimes you don't get all the information and the temptation is then to take a short-cut and maybe not contact the school, or because the school are on holidays you say I think I've got sufficient information to make a decision- NFA

Needless to say, school holidays are not factored into the 7 day timescale! Neither are parents and children who are not at home, nor health visitors who are on sick leave and so forth. These factors necessarily interrupt the expeditiousness of the assessment process, but the system offers no accommodation for the individual tasked with the work. Thus, timescales can create perverse incentives to dispose early on the basis of incomplete information. Whilst in many cases, an "NFA" decision may be quite appropriate, our file analysis of open cases did find a common pattern of repeated initial assessments of escalating severity, before the case eventually found its way through the front-door.

Front-line team managers played a key role in the operation of ICS. In some teams, acutely aware of the possibility of error, managers worked closely alongside new recruits to defuse their inevitable frustrations and induct them into 'local methods' which would enable them to get them to the best out of ICS. Managers could play a key role in mitigating the potential for errors in ICS, via detailed supervision of worker's practices, as the following extract indicates:

Team Manager: I always look at what the referrals were saying what the concerns were at that particular time and then I look at the initial assessment to see if they have covered the history and whether they have identified repeated patterns of concern 
However, we also found some tension between workers and their managers regarding the primacy of meeting targets. For example, in a particularly pressurised team, managers described their frustrations with workers spending too much time 'social chatting' or needing lessons in 'diary management'; such critical attitudes would seem likely only to exacerbate work that was already stressful enough. Invoking 'safeguarding' could buy a worker more time, but only in cases where there was a clear moral mandate to set aside the all-important target. The degree of assertiveness required to challenge the performance system could also lead to overt conflict:

Social worker: My manager said to me "why haven't you finished that yet?"... and I said "well the health visitor hasn't called me back"... and they said, "well no, if you've decided that it's family support, then the outcome won't change, whatever they say". I said "I disagree" and of course that information informs my assessment, I'm not putting my name to that.

Where workers were juggling the completion of IAs with serious cases needing pending to progress and further investigation, 'NFA' was described as a welcome relief. Again, we see the latent potential for errors in this expediency; in the busiest of teams and in spite of the good intentions of workers, time precludes, for example, getting back to the referrer to inform him/her of a decision, which closes down any immediate challenge to the categorisation. Seeing 'the child' is a central and critical part of initial assessment. However, even in relation to this imperative, we found worrying short-cuts, as the following extract illustrates:

Social worker: 'My new manager...she comes back and says, it [the IA] doesn't say have you seen the child, it says "has the child been seen?", you can put "yes" and then make it clear that the teacher has seen the child. I thought hmm, I bet the teacher saw Victoria Climbie as well, you know, what's the point me even doing an assessment if I haven't seen the children'

Children are not easy to 'see' under the conditions of initial assessment, for a variety of reasons. First, there is a requirement to see all children irrespective of ages, but older children can be difficult to track down. Second, 'seeing' should involve talking to the child alone to make an assessment of the child's development and needs, but this is hard to achieve within 7 days in a single visit. With initial response to telephone calls increasingly mediated by administrative staff and home visits curtailed to a single visit, the space between help-seeker and help-provider is steadily widening. Skilled workers might attempt to reduce this space, but for many, in the absence of knowledge derived from face-to-face work with families, they fall back on readily auditable, bureaucratic justifications, often offered by fellow professionals, which invoke missed health appointments, school attendance problems and the like. 


\subsection{Completing the Record}

A standardised assessment record invites workers to comment on a range of factors relating to the child, his/her parents or carers and the presenting concerns. A general observation across our sites was the paucity of information recorded on the actual initial assessment document. In one site, we examined 65 records of individual children; the scantness of the information, compounded by the difficulties of piecing together fragments of narrative scattered across multiple boxes ${ }^{4}$, made it very difficult for the reader to glean a holistic picture of the child and his/her family. The IA record presents as a rather badly designed tool, requiring copious information that is difficult to glean from one home visit and from other professionals; it thus invites workers to discard the majority of its sections as irrelevant. With not unsurprising consistency, we found an expedient method of 'front and back-ing' (or 'back-to-back-ing') had spontaneously sprung up across all our sites, wherein middle sections of the document were omitted altogether:

Researcher: 'So what about the middle of the document, because everyone seems to miss this out?

Social worker: What middle document?

Researcher: You know, practitioners are concerned with the referral and the outcome on the back, but what about all those pages in between about the child?

Social worker: (laughing) To me well... yes, there is a page about the child, I would always put in something, depending on what the child is like...I would always put something in, but in IA you wouldn't...this is initial assessment'

It was clear that workers were trying to make the form fit their work, rather than vice versa, as illustrated by the telling statement that 'this is initial assessment'. Whilst most practitioners welcomed the general principle of electronic recording, the Initial Assessment Record was not only overly long, but the standardised questions and sub-headings were not easily adapted for this or that case (c.f. White et al. 2008), so workers went straight to 'analysis' of 'that dreadful form', putting 'nothing-inbetween'. Scrolling through the pages of the record ourselves, we found it difficult to distinguish between the material typed by workers and material already on the form, i.e. the numerous sub-headings and explanatory notes provided. Workers have become experts with the copy-and-paste function, as material is regularly and mechanistically repeated. In addition, the principle that for every family, a record of each child was required, tended to encourage practitioners to produce a general homogenising account that 'fitted' all the children.

Social worker: 'If I know that the IA is more than likely going to turn into no further action, and I know that after I've had my conversation with the

4 The initial assessment form is typically 10 pages in length. Apart from the usual administrative fields for structured data, there are well over twenty free text fields addressing the developmental status of the child and relevant environmental factors: including the child's 'social presentation' or 'self-care skills', the 'family's social integration' etc. 
family, then I will massage the information on each of the children and talk in plural "the children presented",

Whilst workers were clearly attempting to work-around the excessive audit demands of ICS, to salvage some time to spend with families, even the most perfunctory response to audit left too little time for the real work of face-to-face comunication (Peckover et al. 2008; White et al. 2008). The speed with which workers attempted to complete the IA record also meant that errors of recording were common. In the busiest teams, such errors were compounded when 'students' (for example) were asked to catch up with recording cases they knew nothing about! Whilst workers were aware of these errors, they also reported that it was difficult to make corrections as material was 'locked down' in the system after 24 hours. After that period, a worker would have to seek special permission to undertake corrections. Very obvious errors, such as putting a case note in the wrong file might prompt such requests, but simply improving wording was just too much trouble, though vital to comprehensibility.

We have particularly highlighted aspects of risky practice in teams that were under pressure, to demonstrate the latent conditions for error. It was clear that teams with lower referral rates and better resources could manage the tensions better, without the same ingrained recourse to risky short-cuts. However, even here the demands of timescales and performance management appeared to dominate and were not always seen as conducive to good practice with families:

Social Worker: we're told by supervisors to work towards the timescales 'cos it's their indicators isn't it, then they go off to the Department of Health, so you're trying to think of the best outcomes for the family and for the child but ... you're trying to get things done in timescales and cases moved on, they don't want to hold cases in a duty and assessment team so it's moving them on, which is not, it's not always probably in their best interests.

\section{Discussion}

The Platonic approach can be described as Utopian engineering, as opposed to ... piecemeal engineering. The Utopian approach is the more dangerous... the Utopian engineer will claim that mechanical engineers plan even very complicated machinery as a whole and that their blueprints cover not only a certain kind of machinery, but even the whole factory.... (Karl Popper, The Open Society and its Enemies, 1999)

Since the Laming report (2003) there has been a very significant reconfiguration of children's statutory services in the UK. Rigorous information recording and performance management are the mantras of this brave new world; however it is important that the tools we provide for our workers are fit for purpose (Munro, 2005b). We would argue, however, that the increased audit demands of ICS, together with on-going resource constraints, have served to increase the burden on front-line workers (Peckover et al., 2008; Bell et al. 2007). From our analysis, it is clear that the design of the modernised initial assessment system of children's statutory services, as embodied within the ICS, is not only flawed, but that its dysfunctions provide the latent conditions for error. In response to the intractability of the IA process, the 
workers in our study had devised a range of artful "work-arounds". However, errors are inevitable in the context of such expediencies, which have been extemporized simply to maintain an overly rigid workflow. An excessive zeal for structure and standardisation has thus engendered a reversal of the intended outcome; rather than improving safety, the latent conditions for failure have been exacerbated. The principle of chiasmus is the antithesis of simple, deterministic models of change; its precautionary wisdom is writ large here.

The short-cuts that have been fashioned in the "electronic cage" of the ICS typically take the form of early categorisations based on incomplete information, or the fudging of details of a 'home-visit', and so on. As illustrated in our ethnography, it is preferable to dispose of a seemingly nebulous referral in the face of the more immediate performance demands of the ICS. But it is often just those kinds of referrals that appear to be irrelevant, or somebody else's business, that can provide the warning signs of a more serious malaise ${ }^{5}$. Scarcity of resources will inevitably mean that giving priority to one part of the system, the most immediate, will result in cuts in another. (Rustin, 2004). It is no surprise to have found that workers continue to pursue opportunities to deflect incoming work, and dispose of cases on the basis of superficial analysis, or to fall back on fallible heuristics such as "it's probably malicious". Although Clarke (2007) argues that decision-making in public services takes place in less than theoretically optimum conditions, with workers responding to the immediate "exigencies of the here and now", he argues that we should nonetheless aim to "identify the ideal mode of decision-making" (pp. 68-69). In social services, priority needs to be given to reduce the distance between workers, family and community which many studies have cited (by both service users and front-line workers) as central to good practice (Pithouse and Holland 1999; Gray, 2002; Ruch, 2005). We have seen that the performance-driven ICS only detaches the professional further and further from the possibility of meaningful engagement with service users, offering instead a scientistic veneer of codes, risk scores and metrics.

Lipsky's concept of the "street level bureaucrat" (Lipsky, 1980) emphasizes the importance of professional discretion in effective front-line practice in the public services. Lipsky saw such discretion as essential in order to get the job done: "the situations they face are too complex to reduce to prescribed responses". In terms of systems theory, this is simply a reflection of the ineluctable writ of the Law of Requisite variety; discretion is not some incidental feature, it is fundamental to the operation of any "viable system"6. Pithily, the Law thus proclaims "Only variety

\footnotetext{
${ }^{5}$ The Laming report (2003) identified that everyday biases contributing to errors of judgement in Ealing and Brent social services included the treatment of anonymous calls as a priori malicious. Victoria was referred twice by Ms Akhet a family friend who asked to remain anonymous.

${ }^{6}$ The Law was coined by the British psychiatrist W. Ross Ashby, one of the founding fathers of the systems movement in his Introduction to Cybernetics (1956). Imagine a system (e.g. a family) to be "controlled" in the sense that we seek certain desirable outcomes (e.g. children do not suffer harm and achieve their full potential). Variety simply denotes the number of different "states" that the system can be in, which in the case of a human system (e.g. a family) is both large and dynamic. All families are different and the variety of the social care system must therefore possess a comparable degree of variety (repertoire of responses) in order to deal effectively with this variety.
} 
absorbs variety". This, of course, is the exact opposite of the principle of standardisation, which in the limiting case provides for the same response whatever the input. Rules, policies and procedures are all abstractions and intrinsically lack variety; intelligent human agents provide the necessary "variety amplifiers" (Beer, 1994) which enable bureaucratic systems to work effectively. In a different context, Bourdieu (2003) makes the same point in defining the ability to improvise, to adjust responses to local, situated contingencies, as being the hallmark of competent practice.

The findings we present are controversial and are presented in a designedly polemical tone. We draw attention to the multiple opportunities for errors on the part of front-line social work professionals that are exacerbated given the current configuration of inital assessment process and its technological embodiment in the ICS. Performance management is designed to enhance rather than inhibit quality performance, yet our study has found this regime paradoxially worsens the latent conditions for errors. Whilst it is tempting to berate the maverick professional who subverts correct procedure, it is important to remember that there are "good" organisational reasons for such behaviours, i.e. they are an attempt to reconcile the competing elements of the ICS with imperatives to safeguard children and to support families. The latter role, however prominent in current welfare policy, is particularly vulnerable. Perhaps the real tragedy of ICS is that in busy teams, inevitably demands to support families will be routinely subordinated to pressures to maintain workflow.

Although this paper challenges the huge investment in systems of performance management and IT, we are not arguing for a wholesale Luddite abandonment of new modes of governance and new technology. The remedy, we believe, lies elsewhere, in a radically different approach to design, an approach which draws on core sociotechnical precepts of user participation, minimum critical specification and the optimisation of local autonomy (Pava, 1983; Mumford, 2003). Above all, it is essential to found the design of systems on the needs of users and a thorough understanding of their working practices. This insight applies to the design of any artefact, be it a form, a process or a database. The case for user-centred design (UCD) has been cogently made in many design disciplines, including information systems and human-computer interaction (Norman, 1998). The arguments are both ethical and technical. Technically, UCD is essential in order to gain reliable knowledge for designing new tools and processes. Failure to involve users in the development of new systems inevitably engenders alienation, and there were unmistakable signs of practitioner disquiet (complaints of additional workload and excessive "bureaucratization") in pilot studies of the ICS (Cleaver and Walker, 2004; Cleaver et al., 2008; Bell et al., 2007). It is regrettable that such early warning signals apparently went unheeded, written off as "implementation issues" rather than more fundamental problems of design dogma. As a result, the strictures of the work regime imposed by ICS have not only produced unsafe practices but are now provoking overt resistance from an increasingly frustrated and mutinous workforce, as we saw in our opening quote.

We believe that new systems and technologies can be developed which both assist the users in their daily work and achieve desired organisational goals, but without an ethnographically-informed understanding of human practice (such as this paper provides), this virtuous circle will not be achieved. Ethnographic studies have shown time and again that even work which seems highly routine is a skilled accomplishment 
(Gasser, 1986); its orderliness is a product of the artful worker, not determined by the imposition of a formal rule-base. It is noteworthy that some design methods explicitly call for ethnographic engagement in order to develop a valid evidence base for design, e.g. the SPRINT methodology which has been specifically developed for the public sector (Wastell et al., 2007). There is no final guarantee against chiasmus, but the deployment of such user-centred approaches certainly offers a less hubristic way forward.

We argued that our findings have relevance beyond the domain of children's services. Certainly, there appear to be parallel examples of similar problems in other large scale IT-enabled modernisation projects, such as the gargantuan National Programme for Information Technology (NPfIT) in the UK health service. Eason (2007, p. 258) argues that NPfIT has generally followed a "push strategy, thrusting new technology into the healthcare practices of the NHS", leaving little room for local design. Eason finds strikingly similar local adaptations (workarounds etc.) to those we have unveiled here, as well equally concerning symptoms of stress and mis-use. He goes on to argue a similar case for a flexible socio-technical approach fostering local diversity and based squarely on user needs. The command-and-control, performance management regime (combining "targets and terror") which we have seen in children's services is also pervasive across all UK public services, producing a common pattern of dysfunctional effects (Bevan and Hood, 2006). It is surely time to move away from such crude managerialism. Rather than pressing ever more urgently the cause of bureaucracy over professionalism, salvation may lie in reversing the direction of travel, of relaxing rather than tightening control. Indeed, this the direction suggested by the research evidence. Whilst setting targets and goals can improve performance, doing so in a participative way is known to be more effective that imposing them by fiat, especially for complex, uncertain tasks that cannot readily be routinized (Lock and Latham, 2002). It would seem perverse to continue to ignore such evidence.

\section{Acknowledgements}

This research was funded by the ESRC Public Services Programme: Quality, Performance and Delivery, grant number Res-166-25-0048.

\section{References}

Argyris, C.: On organizational learning. Blackwell, Malden (1999)

Ashby, W.R.: An Introduction to Cybernetics. Chapman and Hall, Boca Raton (1956)

Audit Commission, Recruitment and Retention: A Public Service Workforce for the 21st Century, London, The Stationery Office (2002)

Beer, S.: The Heart of Enterprise. Wiley, Chichester (1994)

Bell, M., Shaw, I., Sinclair, I., Sloper, P., Rafferty, J.: The Integrated Children's System: An

Evaluation of the Practice, Process and Consequences of the ICS in Councils with Social Services Responsibilities. A report to the DfES and the Welsh Assembly, University of York and University of Southampton (2007) 
Bevan, Hood, C.: What get's measured is what matters: targets and gaming in the English public health care system. Public Administration 84(3), 517-538 (2006)

Beynon-Davies, P.: Business Information Systems. Palgrave-Macmillan, Basingstoke (2009)

Bostock, L., Bairstow, S., Fish, S., Macleod, F.: Managing risk and minimizing mistakes in services to children and families. Report 6, London, The Social Care Institute for Excellence (2005)

Bourdieu, P.: Outline of a theory of practice. Cambridge University Press, Cambridge (2003)

Clarke, C.: Professional Responsibility, Misconduct and Practical Reason. Ethics and Social Welfare 1(1), 56-75 (2007)

Cleaver, H., Walker, S.: From policy to practice: the implementation of a new framework for social work assessments of children and families. Child and Family Social Work 9, 81-90 (2004)

Cleaver, H., Walker, S., Scott, S., Cleaver, D., Rose, W., Ward, H., Pithouse, A.: The Integrated Children's System: enhancing social work and inter-agency practice. Jessica Kingsley Publishers, London (2008)

Department for Education and Skills, Every Child Matters, London, The Stationery Office (2003)

Eason, K.: Local socio-technical development in the National Programme for Information Technology. Journal of Information Technology 22, 257-264 (2007)

Gasser, L.: The integration of computing and routine work. ACM Transactions on Office Information Systems 4, 205-225 (1986)

Gray: Emotional labour and befriending in family support and child protection in Tower Hamlets. Child and Family Social Work 7, 13-22 (2002)

Horwath, J.: Maintaining a focus on the Child? Child Abuse Review 11, 195-213 (2002)

Laming, H.: The Victoria Climbie Inquiry: Report of an Inquiry by Lord Laming, Command 5730, Norwich, Stationery Office (2003)

Edwin, A., Locke, E.A.: University of Maryland

Locke, E.A., Latham, G.P.: Building a Practically Useful Theory of Goal Setting and Task Motivation: a 35-Year Odyssey. American Psychologist 57(9), 705-717 (2002)

Lowe, C.M.: Accidents waiting to happen: the contribution of latent conditions to patient safety. Quality and Safety in Health Care 15(suppl. 1), 172-175 (2006)

Lipsky, M.: Street-level Bureaucracy; Dilemmas of the Individual in Public Services. Russell Sage Foundation, New York (1980)

Markus, M.L.: Power, politics and MIS implementation. Communications of the ACM 26(6), 430-444 (1983)

McLuhan, M., Carson, D.: The book of probes. Ginkgo Press (2003)

Mumford, E.: Redesigning human systems. Information Science Publishing (2003)

Munro, E.: What tools do we need to improve identification of child abuse? Child Abuse Review 14(6), 374-388 (2005a)

Munro, E.: A systems approach to investigating child abuse deaths. British Journal of Social Work 25, 531-546 (2005b)

Norman, D.A.: The 'problem' with automation: inappropriate feedback and interaction, not 'over-automation'. Philosophical Transactions of the Royal Society B327, 585-593 (1990)

Norman, D.A.: The design of everyday things. MIT Press, Cambridge (1998)

Pava, C.H.P.: Managing new office technology; an organizational strategy. The Free Press (1983)

Peckover, S., White, S., Hall, C.: Making and managing Electronic Children: e-assessment in child welfare. Information Communication and Society 11(3), 375-394 (2008) 
Pithouse, A., Holland, S.: Open access family centres and their users: positive results, some doubts and new departures. Children and Society 13, 167-178 (1999)

Reason, J.: Managing the risks of organizational accidents. Aldershot, Ashgate (1997)

Reason, J.: Human Error: models and management. British Medical Journal 320, 768-770 (2000)

Ruch, G.: Relationship-based practice and reflective practice, holistic approaches to contemporary child care social work. Child and Family Social Work 10, 111-123 (2005)

Rustin, M.: Learning from the Victoria Climbie Inquiry. Journal of Social Work Practice 18(1), 9-18 (2004)

Unison. Unison memorandum to Lord Laming: Progress report on safeguarding (December 2008)

Wastell, D.G.: Information systems and evidence-based policy in multi-agency networks: the micro-politics of situated innovation. Journal of Strategic Information Systems 1, 77-98 (2006)

Wastell, D.G., McMaster, T., Kawalek, P.: The rise of the Phoenix: methodological innovation as a discourse of renewal. Journal of Information Technology 22, 59-68 (2007)

White, S., Hall, C., Peckover, S.: The descriptive tyranny of the common assessment framework: technologies of categorisation and professional practice in child welfare. British Journal of Social Work, 1-21 (April 2008) 